\title{
Kepemimpinan paternalistis dan perilaku keselamatan kerja: Kepercayaan terhadap supervisor sebagai mediator
}

\author{
Keifan Adi Prasetyo \& Debora Eflina Purba* \\ Fakultas Psikologi, Universitas Indonesia, Depok, Jawa Barat
}

\begin{abstract}
Abstrak
Keselamatan dan Kesehatan Kerja wajib diterapkan oleh setiap industri yang memiliki setidaknya 100 orang pekerja dan industri yang memiliki risiko bahaya tinggi di lingkungan kerjanya. Penelitian ini ingin mengetahui bagaimana pengaruh gaya kepemimpinan yang khas di Indonesia yakni kepemimpinan paternalistis, terhadap perilaku keselamatan kerja karyawan di tempat kerja lewat kepercayaan terhadap supervisor (trust in supervisor) sebagai variabel mediator mengacu pada teori identitas sosial. Penelitian ini menggunakan survei secara daring yang melibatkan karyawan yang bekerja di berbagai sektor industri dengan risiko kecelakaan kerja yang tinggi $(N=300)$. Teknik pengambilan sampel yang digunakan adalah convenience sampling, dan analisis data menggunakan macro PROCESS ver 3.5.3 dari Hayes untuk SPSS ver 26. Hasil penelitian menunjukkan bahwa affective trust tidak memediasi hubungan antara kepemimpinan paternalistis dan perilaku keselamatan kerja, tetapi cognitive trust memediasi hubungan antara kepemimpinan paternalistis dan perilaku keselamatan kerja. Terakhir, affective trust dan cognitive trust secara berurutan memediasi hubungan kepemimpinan paternalistis dan perilaku keselamatan kerja.
\end{abstract}

Kata Kunci: affective trust, cognitive trust, kepemimpinan paternalistis, perilaku keselamatan kerja, trust in supervisor, identitas sosial

\begin{abstract}
Occupational safety and health measures must be applied by every industry that has at least 100 workers and industries that have a high risk of danger in their work environment. This research aims to examine the influence of a typical leadership style in Indonesia, namely paternalistic leadership, on the safety behavior of employees in the workplace via trust in the supervisor as the mediator refers to social identity theory. Trust in supervisors is conceptualized as separate dimensions of affective trust and cognitive trust. The data were taken using convenience sampling using online survey research conducted in various Indonesian industrial sectors with a high risk of work accidents $(\mathrm{N}=300)$. Data were analyzed using Hayes' PROCESS macro ver 3.5.3 on SPSS ver. 26. Results showed that affective trust did not mediate the relationship between paternalistic leadership and safety behavior, but cognitive trust mediated the relationship. Results also showed that affective trust and cognitive trust consecutively mediated the relationship between paternalistic leadership and safety behavior.
\end{abstract}

Keywords: paternalistic, safety, trust in supervisor, leadership, safety behavior, social identity

\section{Pendahuluan}

Sepanjang tahun 2017 BPJS Ketenagakerjaan melaporkan bahwa ada sebanyak 123.041 kasus kecelakaan kerja yang terjadi di Indonesia. Sementara pada semester pertama tahun 2019 tercatat 85.109 kasus kecelakaan mulai dari kecelakaan ringan hingga kecelakaan berat. Pada tahun 2020 di periode yang sama, angka ini meningkat sebanyak $128 \%$ yakni menjadi 108.573 kasus kecelakaan kerja. Rata-rata setiap tahunnya, BPJS melayani 130 ribu kecelakaan yang sebagian besar didominasi oleh kasus-kasus kecelakaan kerja di lingkungan pekerjaan yang berkarakter konstruksi (Syarif, 2019). Catatan Kesehatan dan Keselamatan Kerja (K3) pada Industri di Indonesia ini tergolong dalam kategori "poor." Selain itu, kecelakaan kerja berdampak negatif pada perusahaan, dengan meningkatnya project cost dan waktu yang terbuang sia-sia, serta menurunnya moral pekerja, produktivitas bisnis dan reputasi perusahaan (Musa, dkk., 2015; Gonçalves, dkk., 2008).

Kecelakaan kerja seringkali diremehkan banyak orang dalam perusahaan, karena biaya yang dihabiskan perusahaan terkait keselamatan ternyata tidak banyak diperhitungkan. Hofmann dkk. (2003) menjelaskan perusahaan seringkali 
hanya melihat kerugian langsung yang terlihat seperti psikologis dan kerusakan reputasi ataupun merk produk dari perusahaan. Hal ini sesuai dengan teori accident lost iceberg yang dikemukakan oleh Bird dan Germain (1996) di mana kerugian materil yang diakibatkan oleh kecelakaan kerja tidak hanya disebabkan oleh biaya langsung tapi juga biaya tidak langsung. Dalam accident lost iceberg theory dijelaskan bahwa biaya langsung yang umumnya terlihat yaitu biaya pengobatan dan perawatan hingga biaya asuransi. Sementara ada biaya lain yang jauh lebih besar yang harus dikeluarkan perusahaan apabila terjadi kecelakaan kerja. Biaya tersebut seperti biaya kerusakan bangunan, kerusakan alat dan mesin, down time machine akibat tidak adanya man power atau mesin yang rusak hingga hilangnya waktu kerja akibat investigasi penyebab kecelakaan. Dengan kata lain, apabila terjadi kecelakaan kerja, yang terlihat hanyalah kerugian langsung yang diibaratkan seperti permukaan gunung es.

Faktor penyebab kecelakaan terbesar di lingkungan pekerjaan didominasi oleh perilaku manusia yang tidak aman. Berdasarkan penelitian yang dilakukan oleh NSC (National Safety Council) (2011), 88\% kecelakaan kerja disebabkan oleh unsafe behavior, 10\% disebabkan oleh unsafe condition dan 2\% sisanya tidak diketahui. Beberapa ahli mendefinisikan unsafe behavior sebagai perilaku menyimpang dengan intensi pelanggaran terhadap prosedur standar atau instruksi keselamatan kerja yang dapat menyebabkan terjadinya kesalahan hingga kecelakaan (Fam dkk., 2012; Mohammadfam dkk., 2017; Reason dkk., 1990). Safety behavior (selanjutnya diterjemahkan sebagai perilaku keselamatan kerja) sendiri telah mendapat perhatian dari banyak peneliti terutama pada perusahaan yang memiliki lingkungan kerja yang berbahaya dan berisiko tinggi (Chistian dkk., 2009). Griffin dan Neal (2000) menjelaskan bahwa safety behavior merupakan salah satu variabel kinerja karyawan di tempat kerja, dan didefinisikan sebagai perilaku keselamatan kerja aktual yang ditunjukkan karyawan di lingkungan kerja (Griffin \& Neal, 2000; Neal \& Griffin, 2006).

Neal dan Griffin (2006) dalam penelitiannya membagi 2 tipe perilaku keselamatan kerja yaitu safety compliance dan safety participation. Safety compliance mengarah kepada kedisiplinan karyawan dalam melakukan "prosedur" keselamatan di lingkungan kerja seperti menggunakan alat pelindung diri, melaksanakan log out tag out (LOTO) di mana mereka mengisolasi mesin dan peralatan berbahaya yang sedang mengalami perawatan atau perbaikan sehingga tidak ada orang yang secara sengaja mengoperasikannya saat peralatan tersebut sedang tidak dapat digunakan dan mentaati peraturan keselamatan. Sementara safety participation berada satu level di atas safety compliance yaitu mengarah kepada perilaku karyawan yang secara aktif dan inisiatif membantu perusahaan dalam mengembangkan lingkungan kerja agar selalu dalam keadaan "aman" seperti terlibat dalam komite Kesehatan dan Keselamatan Kerja (K3) hingga menegur orang lain yang melanggar prosedur keselamatan di tempat kerja.

Telah cukup banyak penelitian yang dilakukan untuk mengidentifikasi penyebab perilaku keselamatan kerja karyawan. Christian dkk. (2009) menggolongkan faktor penyebab tersebut menjadi dua golongan, yaitu person-related dan situation-related variables. Klasifikasi ini dikembangkan berdasarkan model safety workplace yang digagas oleh Griffin dan Neal (2000). Personrelated mencakup pengetahuan tentang keselamatan, motivasi keselamatan individu dan faktorfaktor kepribadian dari individu (seperti altruism dan conscientiousness). Pengetahuan merupakan faktor penentu langsung dari performansi seseorang (Griffin \& Neal, 2000). Singkatnya seseorang yang berpengetahuan akan berperilaku aman di tempat kerja sebagai bentuk preventif. Motivasi keselamatan mencerminkan kesediaan individu untuk mengerahkan upaya untuk melakukan perilaku aman. Individu yang memiliki safety motivation yang tinggi cenderung mematuhi peraturan keselamatan dan prosedur yang berlaku (Christian dkk., 2009). Sementara individu yang memiliki faktor kepribadian altruism akan lebih berpartisipasi dalam melaksanakan prosedur keselamatan sebagai bentuk kepedulian terhadap keamanan bersama dalam bekerja (Zohar, 2010).

Sementara itu, situation-related variables meliputi beberapa variabel seperti komitmen manajemen, praktik SDM, sistem keamanan, dukungan atasan, proses internal kelompok, risiko, dan tekanan pekerjaan (Griffin \& Neal, 2000; Neal, 2002). Pada konteks organisasi, seringkali intervensi yang dilakukan untuk meningkatkan perilaku positif karyawan adalah dengan cara meningkatkan variabel situation-related daripada variabel person-related (Griffin \& Neal, 2000; Purba dkk., 2016). Contoh variabel situationrelated yang sering diintervensi untuk menurunkan angka kecelakaan kerja adalah supervisor support, safety climate, proses internal kelompok hingga Human Resources Management Practice (HRMP) (Christian dkk., 2009; Hardison dkk., 2014). Pengaruh gaya kepemimpinan dari atasan langsung dan praktik komunikasi yang terjadi di lapangan menjadi penting agar karyawan menunjukkan perilaku yang diharapkan organisasi dalam hal ini keselamatan kerja, oleh karena itu pengambilan keputusan dan peran manajerial sangat penting dalam menegakkan peraturan 
tentang Kesehatan dan Keselamatan Kerja (K3) (Fruhen dkk., 2014; Lingard dkk., 2019). Dalam beberapa kasus, implementasi manajemen yang buruk dari atasan dan kepemimpinan yang tidak efektif memang tidak berdampak langsung pada kecelakaan fatal namun hal ini sering diidentifikasikan sebagai akar penyebab dari terjadinya kecelakaan kerja (Jia dkk., 2020; Lingard dkk., 2019). Oleh karena itu, manajemen puncak hingga atasan langsung adalah orang yang harus berperilaku tepat untuk memengaruhi perilaku keselamatan kerja seluruh karyawan yang sifatnya "abadi" (Clarke, 2013; Flin \& Yule, 2004). Lebih lanjut Flin dan Yule (2004) menjelaskan manajemen puncak berfungsi sebagai pembuat kebijakan dan representasi organisasi dalam komitmen tentang K3 dan atasan langsung di lapangan yang akan menjadi pengawas jalannya kebijakan sesuai prosedur yang telah ditetapkan.

Kepemimpinan merupakan praktik di mana orang lain dipengaruhi untuk melakukan sesuatu melalui interaksi (Crevani dkk., 2010). Ketidakhadiran pemimpin dalam mempromosikan perilaku keselamatan kerja yang ekstra akan memainkan peran kunci dari sebagian besar cedera dan kematian pekerja di sektor industri dan manufaktur (Cooper, 2015). Akan tetapi, penelitian terdahulu masih sedikit memberikan wawasan tentang jenis perilaku pemimpin yang dapat memprediksi perilaku keselamatan kerja karyawan di tempat kerja (Clarke, 2013). Penelitian yang pernah dilakukan menemukan bahwa pemimpin gaya kepemimpinan transformasional berpengaruh positif dan signifikan pada perilaku keselamatan kerja karyawan. Kepemimpinan transformasional akan mengarah pada kepatuhan karyawan dalam melaksanakan perilaku keselamatan kerja, tetapi lebih jauh lagi akan mendorong partisipasi keselamatan, sebagai bentuk perilaku keselamatan kerja (Clarke, 2013; Lee dkk., 2011; Mullen \& Kevin Kelloway, 2009). Di sisi lain, kepemimpinan transaksional akan lebih terkait erat dengan penekanan pada kepatuhan berbasis aturan karena gaya kepemimpinan ini dicirikan oleh pemantauan aktif karyawan. Sepengetahuan peneliti, dari sekian banyak teori mengenai pengaruh gaya kepemimpinan pada perilaku keselamatan kerja kerja, hanya gaya kepemimpinan transformasional, transaksional dan servant leadership pernah yang diteliti sebagai variabel kepemimpinan yang memengaruhi perilaku keselamatan kerja karyawan (Barling dkk., 2002; Lee dkk., 2011; Mullen \& Kevin Kelloway, 2009). Bahkan, Cooper (2015) menggolongkan gaya kepemimpinan transaksional, transformasional dan melayani sebagai safety leadership. Clarke (2013) dalam penelitian metaanalisisnya menyatakan bahwa perlu dilakukan penelitian lebih lanjut tentang gaya kepemim- pinan lain yang mungkin dapat mempengaruhi perilaku keselamatan kerja karyawan di tempat kerja.

Gaya kepemimpinan yang diterima secara normatif di Indonesia adalah jenis gaya kepemimpinan yang memiliki karakter khusus dan spesifik yakni sangat menjunjung tinggi nilai harmonitas, hirarki dan kerukunan dalam bermasyarakat terutama gaya kepemimpinan dari budaya jawa yang memiliki implikasi langsung terhadap sosok pemimpin yang bersifat ke"bapak"an (Irawanto dkk., 2012). Irawanto (2009) menjelaskan bahwa di negara yang menganut nilai kolektivisme dan high power distance, pemimpin yang tegas, baik hati dan bermoral penuh akan menciptakan hubungan antar manusia yang hangat. Lebih lanjut Hofstede dkk. (2010) menjelaskan bahwa Indonesia merupakan negara yang memiliki skor nilai individualisme sebesar 14 , jauh lebih rendah dibandingkan dengan ranking tertinggi di dunia yakni 43 dan memiliki skor nilai power distance sebesar 78, lebih besar dibandingkan rata-rata nilai dari Negara-negara di Asia yakni sebesar 71. Hal ini menandakan bahwa masyarakat Indonesia adalah masyarakat kolektif dan dependen terhadap hirarki (Hofstede dkk., 2010). Gaya kepemimpinan semacam ini dikenal dengan gaya kepemimpinan paternalistis, yang menggabungkan disiplin yang kuat dengan cara "kebapakan", kebajikan dan integritas moral dalam suasana dan hubungan yang lebih personal (Cheng dkk., 2004; Irawanto dkk., 2012; Irawanto \& Ramsey, 2011). Penelitian ini ingin melihat bagaimana hubungan antara kepemimpinan paternalistis dan perilaku keselamatan kerja karyawan pada beberapa organisasi yang menerapkan aturan Kesehatan dan Keselamatan Kerja secara ketat kepada karyawannya. Ditambah lagi, sejauh ini belum ada penelitian yang mencoba melihat bagaimana pengaruh kepemimpinan paternalistis terhadap perilaku keselamatan kerja.

Kepemimpinan paternalistis yang lebih banyak muncul dalam konteks budaya timur sejatinya adalah gaya kepemimpinan yang terdiri dari tiga dimensi yaitu authoritarian, benevolent dan morale leadership (Cheng dkk., 2004). Lewat penelitiannya di China, Cheng dkk. (2004) menamakan dimensi kepemimpinan paternalistis dengan istilah triad model dan menjelaskan bahwa paternalistis merupakan gaya kepemimpinan yang erat dengan nilai kebudayaan yakni confucianism. Konsep dan dimensi paternalistis yang digagas oleh Cheng dkk. (2004) telah berkembang sedemikian rupa hingga Irawanto dkk. (2012) menggagas PLI (Paternalistic Leadership Indonesia) yang terdiri dari 7 dimensi dari kepemimpinan paternalistis, yaitu pemimpin sebagai pemberi contoh terlihat (visible), pemimpin yang 
memiliki karakter tegas dan otoriter (authoritarian), pemimpin yang baik hati dan berorientasi pada tugas dan anggota timnya (benevolent), pemimpin yang menjunjung tinggi moralitas dengan perilaku incorruptness, pemimpin yang kuat dan berani (moral-courage), tidak memihak (moral-impartialness), juga murah hati dan terbuka terhadap kritik (moral-magnaminty). Irawanto dkk. (2012) menjelaskan lebih lanjut bahwa apabila paternalistis di China kental dengan ciri khas Confucianisme-nya, maka di Indonesia sebagai negara high power distance, sangat kental dengan ciri khas "father-ism" (kebapakan). Konsep "kebapakan" ini berasal dari norma masyarakat budaya Jawa yang memiliki karakteristik dan nilai mengenai "kekeluargaan" (familyism) dan "kebapakan" (father-ism) tercermin dalam sebagian besar gaya kepemimpinan yang muncul pada organisasi di Indonesia (Irawanto dkk., 2012). Sementara itu, Chughtai dkk. (2015) dalam penelitiannya menjelaskan bahwa pengaruh perilaku pemimpin terhadap hasil kerja karyawan tidak dapat dipahami dengan baik tanpa mempertimbangkan mekanisme psikologis yang mungkin mendasarinya. Beberapa penelitian sebelumnya mencoba mengeksplorasi beberapa variabel mediator yang menghubungkan perilaku pemimpin (transaksional dan transformasional) dan perilaku keselamatan kerja, seperti individual motivation, job autonomy, self-efficacy dan trust (Chughtai dkk., 2015; Enwereuzor dkk., 2020; Griffin \& Neal, 2000; Jiang dkk., 2017).

Berangkat dari pernyataan Haslam dkk. (2013) bahwa efektivitas kepemimpinan tergantung pada konteks, penelitian ini menggunakan kerangka social identity theory (teori identitas sosial (Tajfel, 1972) untuk memahami efek dari kepemimpinan paternalistis pada perilaku keselamatan kerja. Teori identitas sosial merujuk pada internalisasi individu bahwa ia merupakan anggota dari sebuah kelompok, dan keanggotaan pada kelompok tersebut penting dan bermakna bagi individu (Tajfel, 1972). Identitas sosial menunjukkan kesediaan individu untuk merujuk dirinya dan orang dalam kelompoknya sebagai "kita", sedangkan "kita" merupakan inti dari kepemimpinan yang efektif (Haslam dkk., 2010). Kepemimpinan paternalistis merupakan gaya kepemimpinan yang secara normatif diterima oleh orang Indonesia. Karyawan mengharapkan atasan langsung mereka untuk bertindak sebagai "bapak" (ayah), yang menyediakan lingkungan kerja yang aman dan perhatian holistik atas kesejahteraan mereka (Purba dkk., 2016). Ketika harapan tersebut terfasilitasi, karyawan akan mengidentifikasikan diri sebagai anggota keluarga dari organisasi dan bersedia menampilkan perilaku keselamatan kerja sesuai dengan peraturan organisasi. Selain itu, pemimpin yang ber- tindak sebagai ayah akan memberikan perhatian dan contoh, dan perhatian secara personal yang tulus dan baik. Penelitian terdahulu juga telah membuktikan bahwa perilaku pemimpin yang menimbulkan kepercayaan dari bawahannya akan membuat bawahan menimbulkan perilaku promotif seperti engagement, embeddedness, loyalty, perilaku extra role juga citizenship behavior (Chughtai dkk., 2015; Detert \& Burris, 2007; Enwereuzor dkk., 2020; Purba dkk., 2016) termasuk di dalamnya perilaku keselamatan kerja. Penelitian ini berkontribusi pada penelitian terkait perilaku keamanan dengan melihat mekanisme psikologis yang mendasari hubungan antara kepemimpinan paternalistis dengan perilaku keamanan karyawan.

Masih menggunakan teori identitas sosial, atasan yang berhasil menumbuhkan sikap "kita" pada karyawannya akan menumbuhkan rasa percaya (trust in supervisor) pada karyawannya dan pada akhirnya akan meningkatkan perilaku keselamatan kerja yang merupakan perilaku positif yang diinginkan oleh atasannya. Dalam hubungan interpersonal, struktur trust dapat dibedakan berdasarkan sumbernya yakni rasionalitas dan emosi. Erdem (2003) menjelaskan bahwa perbedaan ini dapat menghasilkan kualitas kepercayaan yang berbeda dan umumnya dikenal dengan cognitive dan affective trust. Ketika seorang bawahan memiliki kepercayaan terhadap atasan mereka berdasarkan alasan yang rasional dan faktual, seperti kinerja atasan dan wibawa, maka ini disebut dengan cognitive trust. Di sisi lain, ketika bawahan menaruh kepercayaan terhadap atasan karena komunikasi yang intensif dengan atasan, hubungan emosional yang kuat dan perasaan saling menguntungkan antara kedua belah pihak, maka ini disebut dengan affective trust (Erdem \& Ozen, 2003). Dirk dan Ferrin (2002) mengemukakan kerangka berpikir yang memisahkan konsekuensi affective trust yang didasarkan pada kualitas hubungan antara atasan dan karyawan, dan cognitive trust yang didasarkan pada persepsi karyawan pada karakter atasan yang diinginkan oleh karyawan. Kedua jenis trust ini kemudian memiliki mekanisme yang berbeda dalam memengaruhi perilaku karyawan (Dirk \& Ferrin, 2002; Newman dkk., 2013; Zhu dkk., 2013). Cognitive trust yang didasarkan pada karakter atasan akan memengaruhi karyawan secara hierarkis, dimana atasan yang dipersepsikan memiliki karakter integritas, kompetensi, dan baik hati akan membuat karyawan lebih nyaman menampilkan perilaku yang berisiko, seperti membagi informasi yang sensitif. Sementara itu, affective trust yang didasarkan pada kualitas hubungan atasan dan karyawan, memengaruhi karyawan dengan cara pemberian kepedulian, perhatian, dan pertimbangan yang 
lebih personal yang membuat karyawan memercayai atasannya selayaknya seorang bapak yang melindungi dan mengayomi anaknya.

Newman dkk. (2013) menemukan mekanisme kausal antara cognitive trust dan affective trust menggunakan teori pertukaran sosial, di mana ethical leadership secara tidak langsung memengaruhi perilaku OCB karyawan lewat cognitive trust dan affective trust, secara berurutan. Berbeda dengan Newman dkk. (2013), peneliti berargumentasi bahwa affective trust memegang peran penting sebagai fondasi pada pengembangan persepsi positif karyawan pada kualitas karakter atasannya, dan hanya cognitive trustyang memiliki hubungan langsung dengan perilaku keamanan karyawan. Oleh karena itu, peneliti mengusulkan model mediasi tiga jalur, dimana kepemimpinan paternalistis akan memengaruhi perilaku keamanan karyawan lewat dua mediator secara berurutan, yaitu affective trust dan cognitive trust. Dengan demikian, penelitian ini juga berkontribusi pada penelitian trust in supervisor dengan menemukan arah yang baru pada hubungan antara affective trust dan cognitive trust. Peneliti berargumentasi bahwa kepemimpinan paternalistis akan terlebih dahulu memengaruhi affective trust, kemudian cognitive trust, dan akhirnya perilaku keselamatan kerja karyawan. Dalam hal ini, karyawan yang mempersepsikan atasannya bertindak seperti seorang "bapak" yang mengayomi, tegas, peduli, dan memiliki moral yang tinggi, akan mengidentifikasikan dirinya dengan atasannya dan menganggap atasan tersebut sebagai bagian dari keluarganya. Kepercayaan karyawan bahwa atasannya peduli dan akan memenuhi kebutuhannya di tempat kerja akan mendorong karyawan berani mengomunikasikan perasaannya pada atasan dan merasa nyaman dalam berhubungan dengan atasannya. Perasaan nyaman berhubungan dengan atasannya ini kemudian akan membentuk cognitive trust terhadap atasannya, ketika karyawan menganggap atasannya adalah seorang yang bertanggung jawab, memiliki integritas dan kompetensi sebagai pengambil keputusan yang terbaik. Persepsi yang positif pada karakter atasannya pada gilirannya akan meningkatkan perilaku keamanan di tempat kerja. Dengan demikian, hipotesis penelitian ini adalah: "Kepemimpinan paternalistis memprediksi perilaku keselamatan kerja melalui affective trust dan cognitive trust secara berurutan."

\section{Metode Penelitian}

\section{Partisipan}

Partisipan dalam penelitian ini adalah karyawan yang bekerja di tiga perusahaan manufak- tur yang berada di daerah Jabodetabek. Kriteria partisipan adalah: (1) masa kerja minimal satu tahun di perusahaan tersebut, dan (2) bekerja pada lingkungan kerja yang berbahaya dan membutuhkan Alat Pelindung Diri (APD). Kriteria masa kerja minimal 1 tahun di perusahaan adalah karena masa kerja di atas 1 tahun diasumsikan telah mengenal dengan baik situasi dan kondisi tempat ia bekerja sehingga respon yang didapatkan akan lebih akurat (Zhao, 2014). Sementara itu, bekerja pada lingkungan kerja yang berbahaya dan membutuhkan APD dalam melakukan aktivitas pekerjaannya adalah karena jenis pekerjaan ini akan lebih menggambarkan variabel yang ingin diukur yakni perilaku keselamatan kerja.

Teknik pengambilan sampel yang digunakan adalah non-probability sampling karena tidak adanya kesempatan yang sama pada setiap individu yang menjadi populasi untuk menjadi sampel. Pengambilan sampel dilakukan dengan cara convenience sampling, dimana partisipan yang terlibat adalah mereka yang mendapatkan akses survei daring dan menyatakan kesediaan untuk berpartisipasi. Jumlah partisipan yang bersedia berpartisipasi dalam penelitian ini adalah 322 orang. Sebanyak 32 partisipan tidak diikutsertakan di dalam analisis data karena mereka tidak memenuhi satu dari dua kriteria partisipan yang ditetapkan, yakni masa kerja minimal satu tahun dan wajib menggunakan APD.

Selain itu, peneliti juga memberikan satu item pengecoh untuk lebih memastikan bahwa partisipan mengisi alat ukur dengan baik dan dengan konsentrasi penuh. Item pengecoh tersebut adalah "Susilo Bambang Yudhoyono adalah presiden indonesia saat ini". Peneliti tidak mengikutsertakan 25 partisipan yang merespon pernyataan tersebut dengan pilihan jawaban 3 (agak setuju) hingga 5 (sangat setuju). Dengan demikian, dari 322 yang ikut dalam penelitian ini, terdapat 57 partisipan yang tidak diikutsertakan dalam proses pengolahan data. Dengan demikian, jumlah partisipan yang diikutsertakan dalam analisis selanjutnya adalah 265 orang. Berdasarkan respon yang berhasil diolah oleh peneliti, partisipan dalam penelitian ini terdiri dari $73 \%$ berjenis kelamin Laki-laki dan $27 \%$ berjenis kelamin perempuan. Rata-rata usia dari partisipan dalam penelitian ini adalah 26 tahun $(S D=6,17)$ dan rata-rata lama kerja di perusahaan adalah 3,5 tahun $(S D=4,29)$.

\section{Desain}

Desain yang digunakan dalam penelitian ini adalah non eksperimental dengan pendekatan kuantitatif. Data diambil secara selfreport di mana partisipan diminta untuk menilai dirinya sendiri 
terhadap pernyataan yang telah disusun oleh peneliti. Metode yang digunakan dalam penelitian ini adalah survei daring dengan menggunakan Google Form.

\section{Alat ukur}

Alat ukur kepemimpinan paternalistis diadaptasi dari skala yang dikembangkan oleh Irawanto (2009). Pada penelitian ini, peneliti menggabungkan 4 dimensi morale-incorruptness, morale-courage, morale-impartial, morale-magnaminty menjadi satu dimensi yakni morale leadership sehingga item kepemimpinan paternalistis yang digunakan dalam penelitian ini berjumlah 26 item (9 item visible leadership, 7 item authoritarian leadership, 7 item benevolence leadership, 5 item morale leadership). Reliabilitas untuk skala ini diukur menggunakan Cronbach Alpha yaitu sebesar 0,67 untuk alat ukur visible leadership, 0,87 untuk authoritarian leadership, 0,80 untuk benevolent leadership dan 0,83 untuk morale leadership. Sedangkan reliabilitas keseluruhan konstruk kepemimpinan paternalistis adalah 0,74 .

Trust in supervisor diukur menggunakan skala yang diterjemahkan ke dalam Bahasa Indonesia oleh Purba dkk. (2016) dari skala yang dikembangkan oleh Yang dkk. (2009). Alat ukur ini terdiri dari 5 item yang mewakili dimensi cognitive trust dan 5 item yang mewakili dimensi affective trust. Variabel trust in supervisor diukur dengan menggunakan respon jawab skala Likert yang memiliki 5 pilihan jawaban mulai dari sangat tidak sesuai (1) hingga sangat sesuai (5). Reliabilitas untuk skala ini diukur menggunakan Cronbach Alpha yaitu sebesar 0,74 alat ukur affective trust dan 0,83 untuk alat ukur cognitive trust.

Sementara alat ukur perilaku keselamatan kerja diterjemahkan dari skala yang dikembangkan oleh Neal dan Griffin (2006) dengan melalui proses penerjemahan ke bahasa Indonesia dan uji keterbacaan oleh expert judgement. Alat ukur tersebut terdiri dari 3 item yang mewakili dimensi safety compliance dan 3 item yang mewakili dimensi safety participation. Variabel safety participation diukur dengan menggunakan respon jawab skala Likert yang memiliki 5 pilihan jawaban mulai dari sangat tidak sesuai (1) hingga sangat sesuai (5). Reliabilitas untuk skala ini diukur menggunakan Cronbach Alpha yaitu sebesar 0,66.

Selain variable di atas, peneliti juga memberikan 3 pertanyaan untuk memastikan bahwa partisipan yang ikut serta dalam penelitian ini adalah mereka yang sesuai dengan kriteria penelitian yakni mereka yang bekerja pada lingkungan kerja yang berbahaya dan membutuhkan Alat Pelindung Diri (APD) dalam melakukan aktivitas pekerjaannya. Salah satu contoh pertanyaan yang diajukan dalam skala penelitian adalah "Apakah pekerjaan yang anda lakukan mengharuskan anda menggunakan alat pelindung diri lengkap?"

\section{Prosedur}

Penelitian diawali dengan persiapan alat ukur kepemimpinan paternalistis, trust in supervisor dan perilaku keselamatan. Sebelum melakukan pengujian hipotesis, peneliti terlebih dahulu melakukan uji reliabilitas dan validitas terhadap alat ukur adaptasi. Setelah alat ukur dinyatakan valid dan reliabel berdasarkan uji statistik, peneliti membuat tautan kuesioner ke dalam Google Form agar dapat dibagikan secara daring kepada partisipan penelitian. Untuk mendapatkan responden penelitian, peneliti menghubungi HRD dari beberapa perusahaan di Jabodetabek melalui pesan Whatsapp untuk menginformasikan mengenai ruang lingkup penelitian dan meminta bantuan untuk membagikan kuesioner daring yang telah disiapkan peneliti. Selanjutnya, koordinasi pengumpulan data dilakukan juga melalui pesan daring berupa Whatsapp dan surat elektronik langsung kepada HRD masing-masing perusahaan yang kemudian diteruskan kepada para supervisor di departemen produksi. Partisipan diminta untuk mengunjungi tautan yang disediakan oleh peneliti dan memberikan respons langsung pada Google Form tersebut. Untuk meyakinkan calon partisipan bahwa penelitian ini bersifat rahasia, pada bagian pengantar kuesioner, peneliti menjelaskan bahwa informasi mengenai data yang didapatkan tidak akan disebarluaskan kepada pihak perusahaan. Selain itu, partisipan juga tidak perlu mengisi nama dan identitas pribadi dalam penelitian ini.

\section{Teknik analisis}

Pada penelitian ini peran mediasi akan dianalisis menggunakan macro PROCESS ver 3.5.3 untuk SPSS ver 26 yang dikembangkan oleh Hayes (2013). Hayes (2013) merekomendasikan penggunaan metode bootstrapping untuk menghitung efek tidak langsung yang tidak mengalami keterbatasan dari model efek kausal yang dikembangkan oleh Baron dan Kenny (1986). Process macro memungkinkan peneliti menghasilkan output untuk efek tidak langsung termasuk interval kepercayaan dan effect size. Template yang digunakan untuk dua mediator adalah Model 6, dengan bootstrap 5000 kali pada tingkat kepercayaan 95\%. Melalui analisis ini akan didapatkan pengaruh dari kepemimpinan paternalistis terhadap perilaku keselamatan kerja, baik secara langsung maupun tidak langsung, melalui kedua dimensi trust in supervisor yakni affective trust dan cognitive trust. 


\section{Hasil Penelitian}

Sebelum melakukan uji hipotesis, peneliti terlebih dahulu melakukan analisis korelasi untuk melihat hubungan antar variabel penelitian. Uji korelasi dilakukan dengan menggunakan pearson product moment. Berdasarkan hasil uji korelasi tersebut, kepemimpinan paternalistis memiliki korelasi yang positif signifikan dengan affective trust dan cognitive trust ( $r=0,50, p<0,01 ; r=$ $0,53, p<0,01$ ). Selain itu, terdapat korelasi yang positif signifikan antara perilaku keselamatan kerja dengan affective trust dan cognitive trust ( $r$ $=0,32, p<0,01 ; r=0,47, p<0,01)$. Kepemimpinan paternalistis juga memiliki korelasi yang positif signifikan dengan perilaku keselamatan kerja $(r$ $=0,31, p<0,01)$. Hasil uji korelasi dapat dilihat pada Tabel 1 di bawah ini.

Tabel 1

Mean, deviasi standar, dan korelasi antar variabel penelitian

\begin{tabular}{|c|c|c|c|c|c|c|c|c|}
\hline & $\mathrm{M}$ & SD & 1 & 2 & 3 & 4 & 5 & 6 \\
\hline Usia & 25,69 & 4,29 & 1 & & & & & \\
\hline Lama Kerja & 3,55 & 6,17 & $0,70^{* *}$ & 1 & & & & \\
\hline Kepemimpinan paternalistis & 3,50 & 0,40 & 0,10 & 0,04 & 1 & & & \\
\hline Affective Trust & 3,55 & 0,93 & 0,08 & $-0,08$ & $0.50^{* *}$ & 1 & & \\
\hline Cognitive Trust & 4,12 & 0,74 & 0,04 & $0,-06$ & $0,53^{* *}$ & $0,64^{* *}$ & 1 & \\
\hline Perilaku keselamatan kerja & 4,16 & 0,72 & 0,03 & $-0,01$ & $0,32^{* *}$ & $0,32^{* *}$ & $0,47^{* *}$ & 1 \\
\hline
\end{tabular}

Selanjutnya, peneliti melakukan pengujian hipotesis dengan menggunakan makro PROCESS dari Hayes dengan Model 6. Hasil penelitian yang didapatkan dari Model 6 makro PROCESS memperlihatkan tiga indirect effect, yaitu hubungan tidak langsung antara kepemimpinan paternalistis dan perilaku keselamatan kerja lewat affective trust, hubungan tidak langsung antara kepemimpinan paternalistis dan perilaku keselamatan kerja lewat cognitive trust, dan hubungan tidak langsung antara kepemimpinan paternalistis dan perilaku keselamatan kerja lewat affective trust dan cognitive trust secara berurutan. Dari hasil analisis yang terlihat pada Tabel 2, kepemimpinan paternalistis memprediksi affective trust secara positif dan signifikan $(b=1,15, S E=0,12$, $p<0,01)$ dan cognitive trust $(b=0,51, S E=0,09$, $p<0,01)$. Selain itu, affective trust memprediksi cognitive trust secara positif dan signifikan $(b=$ $0,40, S E=0,04, p<0,01)$. Sebagai analisis tambahan, hasil uji statistik menunjukkan hubungan tidak langsung antara kepemimpinan paternalistis dan perilaku keselamatan kerja melalui variabel affective trust adalah negatif tetapi tidak signifikan $(b=-0,01 S E=0,05, \mathrm{p}<0,001,95 \%$ CI [-0, 1198, 0, 0976]). Hal ini berarti affective trust tidak memediasi hubungan antara kepemimpinan paternalistis dan perilaku keselamatan kerja.

Analisis tambahan kedua menunjukkan bahwa indirect effect antara kepemimpinan paternalistis terhadap perilaku keselamatan kerja melalui cognitive trust adalah positif dan signifi- $\operatorname{kan}(b=0,17, S E=0,05, \mathrm{p}<0,001,95 \%$ CI $[0,0892$, $0,2869])$. Hal ini berarti kepemimpinan paternalistis memprediksi perilaku keselamatan kerja lewat cognitive trust.

Berdasarkan uji hipotesis penelitian, koefisien indirect effect kepemimpinan paternalistis terhadap perilaku keselamatan kerja melalui affective trust dan cognitive trust secara berurutan adalah positif dan signifikan $(b=0,16, S E=$ $0,01,95 \%$ CI $[0,0974,0,2325])$. Hal ini berarti kepemimpinan paternalistis memprediksi perilaku keselamatan kerja melalui affective trust dan cognitive trust secara berurutan. Dengan demikian, hipotesis penelitian ini yang menyatakan bahwa kepemimpinan paternalistis memprediksi perilaku keselamatan kerja melalui affective trust dan cognitive trust secara berurutan didukung oleh data penelitian. Tambahan lagi, berdasarkan hasil analisa juga diketahui bahwa pengaruh langsung (direct effect) kepemimpinan paternalistis terhadap perilaku keselamatan kerja adalah tidak signifikan $(b=0,14, S E=0,10,95 \%$ CI $[0,1529$, $0,0517])$. Artinya, hubungan antara kepemimpinan paternalistis terhadap perilaku keselamatan kerja dimediasi penuh oleh trust in supervisor. Sementara koefisien total effect yaitu hubungan antara kepemimpinan paternalistis dengan perilaku keselamatan kerja tanpa melalui mediator adalah positif signifikan $(b=0,46, S E=0,05$, p < $0,001,95 \%$ CI $[0,2970,0,6336])$. Hasil analisis regresi hipotesis penelitian dapat dilihat pada Tabel 2 di bawah ini. 
Tabel 2

Analisis jalur hubungan antara kepemimpinan paternalistis dan perilaku keselamatan melalui affective trust dan cognitive trust.

\begin{tabular}{|c|c|c|c|c|c|}
\hline \multirow{2}{*}{ Analisis jalur } & \multirow{2}{*}{$b$} & \multirow{2}{*}{$S E$} & \multicolumn{2}{|c|}{$95 \% \mathrm{CI}$} & \multirow{2}{*}{ Signifikansi } \\
\hline & & & LL & UL & \\
\hline $\begin{array}{l}\text { Kepemimpinan paternalistis } \rightarrow \\
\text { affective trust }\end{array}$ & $1,15^{* *}$ & 0,12 & 0,9099 & 1,3940 & Signifikan \\
\hline $\begin{array}{l}\text { Kepemimpinan paternalistis } \rightarrow \\
\text { cognitive trust }\end{array}$ & $0,51^{* *}$ & 0,09 & 0,3242 & 0,6964 & Signifikan \\
\hline Affective trust $\rightarrow$ Cognitive trust & $0,40^{* *}$ & 0,04 & 0,3214 & 0,4830 & Signifikan \\
\hline $\begin{array}{l}\text { Affective trust } \rightarrow \text { Perilaku } \\
\text { keselamatan kerja }\end{array}$ & $-0,01$ & 0,05 & $-0,1016$ & 0,0815 & Tidak signifikan \\
\hline $\begin{array}{l}\text { Cognitive trust } \rightarrow \text { Perilaku } \\
\text { keselamatan kerja }\end{array}$ & $0,35^{* *}$ & 0,06 & 0,2297 & 0,4656 & Signifikan \\
\hline $\begin{array}{l}\text { Kepemimpinan paternalistis } \rightarrow \\
\text { Perilaku keselamatan kerja } \\
\text { (Total effect) } \\
\text { Kepemimpinan paternalistis } \rightarrow\end{array}$ & $0,46^{* *}$ & 0,09 & 0,2970 & 0,6336 & Signifikan \\
\hline $\begin{array}{l}\text { Perilaku keselamatan kerja } \\
\text { (Direct effect) }\end{array}$ & 0,14 & 0,10 & 0,1529 & $-0,0517$ & Tidak signifikan \\
\hline $\begin{array}{l}\text { Kepemimpinan paternalistis } \rightarrow \\
\text { affective trust } \rightarrow \text { Perilaku } \\
\text { keselamatan kerja (Indirect } \\
\text { effect) }\end{array}$ & $-0,01$ & 0,06 & $-0,1198$ & 0,0976 & Tidak signifikan \\
\hline $\begin{array}{l}\text { Kepemimpinan paternalistis } \rightarrow \\
\text { cognitive trust } \rightarrow \text { Perilaku } \\
\text { keselamatan kerja (Indirect } \\
\text { effect) }\end{array}$ & $0,17^{* *}$ & 0,05 & 0,0892 & 0,2869 & Signifikan \\
\hline $\begin{array}{l}\text { Kepemimpinan paternalistis } \rightarrow \\
\text { affective trust } \rightarrow \text { cognitive trust } \\
\rightarrow \text { Perilaku keselamatan kerja } \\
\text { (Indirect effect) }\end{array}$ & $0,16^{* *}$ & 0,03 & 0,0974 & 0,2325 & Signifikan \\
\hline
\end{tabular}

\section{Diskusi}

Penelitian ini bertujuan untuk mengetahui peran mediator dua dimensi trust in supervisor, yaitu affective trust dan cognitive trust, pada hubungan antara kepemimpinan paternalistis dan perilaku keselamatan kerja. Berdasarkan hasil analisis menunjukkan bahwa hipotesis penelitian yang menyatakan bahwa kepemimpinan paternalistis memprediksi perilaku keselamatan kerja lewat affective trust dan cognitive trust secara berurutan didukung oleh data. Dari analisis jalur, hasil penelitian menunjukkan bahwa kepemimpinan paternalistis memiliki hubungan dengan kedua dimensi trust in supervisor, dan hasil ini sesuai dengan beberapa penelitian sebelumnya yang telah menemukan bahwa kepemimpinan paternalistis memiliki pengaruh yang positif signifikan terhadap trust in supervisor (Rawat \& Lyndon, 2016; Tian \& Sanchez, 2017). Perlakuan pemimpin menimbulkan nilai timbal balik yang kuat didukung oleh bawahan yang akan memberikan kepercayaan terhadap pemimpin mereka yang memberi mereka contoh, berperilaku "kebapakan", memberikan perhatian dan perawatan secara personal yang tulus dan baik (Irawanto dkk., 2012).

Penelitian ini berkontribusi dalam menemukan mekanisme baru dari kepemimpinan paternalistis ke affective kemudian cognitive trust. Sebelumnya, Newman dkk. (2013) menemukan mekanisme, di mana kepemimpinan secara tidak langsung memengaruhi perilaku promotif lewat cognitive trust dan affective trust, secara berurutan. Akan tetapi, hasil dari penelitian ini menemukan bahwa affective trust dan cognitive trust secara berurutan menjadi mediator pada pengaruh antara kepemimpinan paternalistis terhadap perilaku keselamatan kerja. Hal tersebut kemungkinan dikarenakan kepemimpinan paternalistis merupakan gaya kepemimpinan yang secara normatif lebih diterima oleh masyarakat Indonesia yang memiliki nilai kolektif dan power distance yang tinggi. Pemimpin paternalistis akan menim- 
bulkan perasaan nyaman dan merasa diperhatikan seperti seorang bapak kepada anak-anaknya, sehingga meningkatkan kepercayaan afektif pada karyawan yang pada gilirannya akan dengan mudah meningkatkan kepercayaan kognitif karena mereka percaya bahwa atasan mereka adalah orang yang bertanggung jawab dalam pekerjaan formal mereka, dan hal ini kemudian akan meningkatkan perilaku keselamatan kerja.

Berdasarkan hasil analisis statistik, affective trust tidak memediasi hubungan antara kepemimpinan paternalistis dan perilaku keselamatan kerja, karena jalur dari affective trust ke perilaku keselamatan kerja tidak signifikan. Kemungkinan penyebab affective trust tidak menjadi mediator secara terpisah dengan cognitive trust pada perilaku keselamatan kerja adalah karena perilaku keselamatan kerja merupakan perilaku positif karyawan yang bertumbuh karena karyawan melihat karakter, kinerja, dan kompetensi atasannya, yang lebih berhubungan dengan cognitive trust dibandingkan affective trust. Ketika seorang karyawan memiliki kepercayaan terhadap atasan mereka berdasarkan alasan yang rasional dan faktual (kinerja atasan, wibawa), mereka akan lebih memperhatikan dan melakukan perilaku keselamatan kerja di tempat kerja. Hal ini menjelaskan dan mendukung penelitian Clarke (2013) di mana faktor penting dalam kaitannya dengan perilaku keselamatan kerja kerja adalah pemimpin harus menjadi contoh dan terlihat "walk the talk" yaitu seperti pemantauan aktif dan intervensi langsung saat masalah terjadi. Pemimpin dengan gaya paternalistis adalah pemimpin yang berperilaku visible yaitu sebagai orang yang bertindak di depan dan menjadi contoh. Mereka juga akan berperilaku tegas dan ketat terhadap bawahannya sehingga perilaku seperti itu akan menghasilkan penguatan perilaku keselamatan kerja sebagai bagian dari prioritas dalam bekerja. Zohar (2010) juga menjelaskan hal serupa di mana prioritas tentang perilaku keselamatan kerja tidak akan berhasil apabila hanya tertuang dalam prosedur dan kebijakan organisasi, melainkan prioritas tersebut tercermin dan dilaksanakan dalam realitas sehari-hari. Tentunya harus ada pengawasan dan keterlibatan langsung dari pemimpin sebagai fungsi pengawasan tersebut.

Peneliti menyadari terdapat kekurangan dalam penelitian ini. Peneliti tidak mengontrol variabel budaya yang mungkin berpengaruh dalam menentukan kriteria partisipan. Hal ini penting karena kepemimpinan paternalistis adalah gaya kepemimpinan yang erat dengan konsep "kebapakan" yang berasal dari norma masyarakat budaya Jawa. Penelitian selanjutnya disarankan untuk melakukan perbandingan budaya antara beberapa etnis yang berbeda sehingga dapat ditarik kesimpulan yang lebih general mengenai kepemimpinan paternalistis yang tepat untuk Indonesia.

\section{Kesimpulan}

Berdasarkan hasil penelitian, dapat disimpulkan bahwa terdapat hubungan tidak langsung antara kepemimpinan paternalistis dan perilaku keselamatan kerja lewat affective trust dan cognitive trust, secara berurutan. Hasil analisis tambahan menunjukkan affective trust tanpa cognitive trust tidak memediasi hubungan antara kepemimpinan paternalistis dan perilaku keselamatan kerja. Selanjutnya, cognitive trust dapat menjadi mediator tunggal dalam hubungan antara kepemimpinan paternalistis dan perilaku keselamatan kerja.

\section{Saran metode dan teoretis}

Penelitian ini memiliki beberapa saran metode dan teoretis bagi penelitian selanjutnya. Penelitian ini bersifat cross sectional, sehingga tidak dapat ditarik kesimpulan hubungan kausal di antara variabel-variabel penelitian. Penelitian selanjutnya disarankan untuk menggunakan metode longitudinal atau eksperimen agar dapat menjelaskan hubungan kausal antar variabel penelitian. Selain itu, semua data diambil secara self report sehingga dapat menimbulkan potensi common method bias (Podsakoff dkk., 2003). Akan tetapi, Harman's first factor analysis menunjukkan bahwa faktor pertama yang muncul dalam analisis faktor hanya menjelaskan 22,8\% varians, lebih kecil dari batas 50\% yang ditetapkan oleh Harman (Podsakoff dkk., 2003), sehingga common method bias tidak memengaruhi hasil penelitian. Meskipun demikian, penelitian selanjutnya disarankan menggunakan metode yang lebih rigorous, seperti mengambil data secara temporal separation, dengan memisahkan pengambilan data prediktor dan outcome, atau menggunakan desain longitudinal (Podsakoff dkk., 2003).

Secara teori, penelitian selanjutnya disarankan untuk mereplikasi urutan affective trust dan cognitive trust dalam hubungan antara kepemimpinan paternalistis dengan variabel kerja lain seperti task performance, organizational citizenship behavior, dan komitmen organisasi.

\section{Saran praktis}

Penelitian ini memiliki beberapa saran praktis. Peneliti menemukan bahwa kepemimpinan paternalistis akan mempengaruhi kepercayaan karyawan terhadap atasan dan pada akhirnya mengakibatkan karyawan melakukan 
perilaku keselamatan kerja di tempat kerja. Melihat hal tersebut, organisasi dapat membuat intervensi berupa program pelatihan yang berfokus pada peningkatan integritas dan gaya kepemimpinan dengan model kekeluargaan seperti halnya pemimpin paternalistis, misalnya dengan memperkenalkan karakteristik pemimpin paternalistis (visible, authoritarian, benevolence dan morale) atau program diklat mengenai integritas pemimpin terhadap core value organisasi. Selain itu, penelitian ini juga menemukan bahwa cognitive trust penting karena berperan sebagai mediator, sehingga organisasi dapat mencegah potensi hilangnya perilaku keselamatan kerja dengan meningkatkan cognitive trust dalam praktik kerja sehari-hari. Salah satu contoh, organisasi dapat membuat pelatihan mengenai dinamika kelompok, membangun sarana komunikasi internal departemen dan membuat project tertentu yang melibatkan dinamika atasan dan bawahan. Selain dapat meningkatkan komunikasi efektif, dinamika kelompok dan project bersama akan meningkatkan kepercayaan atasan dan bawahan baik secara afektif maupun secara kognitif (Elgoibar, dkk., 2016).

\section{Daftar Pustaka}

Abdullah Musa, R., Fadhli, A., Kusminanti, Y., Erwandi, D., \& Lestari, F. (2015). Behaviour intention analysis among workers at oil and gas company. Society of Petroleum Engineers - SPE/IATMI Asia Pacific Oil and Gas Conference and Exhibition, APOGCE 2015. https://doi.org/10.2118/176350-ms

Barling, J., Loughlin, C., \& Kelloway, E. K. (2002). Development and test of a model linking safety-specific transformational leadership and occupational safety. Journal of Applied Psychology, 87(3), 488-496. https://doi.org/10.1037/00219010.87.3.488

Baron, R. M., \& Kenny, D. A. (1986). The moderator-mediator variable distinction in social psychological research: Conceptual, strategic, and statistical considerations. Journal of Personality and Social Psychology, 51(6), 1173-1182. https://doi.org/10.1037//00223514.51.6.1173

Cheng, B. S., Chou, L. F., Wu, T. Y., Huang, M. P., \& Farh, J. L. (2004). Paternalistic leadership and subordinate responses: Establishing a leadership model in Chinese organizations. Asian Journal of Social Psychology, 7, 89117. https://doi.org/10.1111/j.1467839X.2004.00137.X

Chistian, rMichael S., Bradley, J. C., Wallace, J. C., \& Burke, M. J. (2009). Workplace Safety: A
Meta-Analysis of the Roles of Person and Situation Factors. Journal of Applied Psychology, 94(5), 1103-1127. https://doi.org/10.1037/a0016172

Chughtai, A., Byrne, M., \& Flood, B. (2015). Linking Ethical Leadership to Employee Well-Being: The Role of Trust in Supervisor. Journal of Business Ethics, 128(3), 653-663. https://doi.org/10.1007/s10551-0142126-7

Clarke, S. (2013). Safety leadership: A metaanalytic review of transformational and transactional leadership styles as antecedents of safety behaviours. Journal of Occupational and Organizational Psychology, 86(1), 22-49. https://doi.org/10.1111/j.20448325.2012.02064.x

Cooper, D. (2015). Effective safety leadership: Understanding types \& styles that improve safety performance. Professional Safety, 60(2), 49-53 http://www.asse.org/professional-safety/

Crevani, L., Lindgren, M., \& Packendorff, J. (2010). Leadership, not leaders: On the study of leadership as practices and interactions. Scandinavian Journal of Management, 26(1), 77-86.

https://doi.org/10.1016/j.scaman.2009.12. 003

Detert, J. R., \& Burris, E. R. (2007). Leadership behavior and employee voice: Is the door really open? Academy of Management Journal, 50(4), 869-884. https://doi.org/10.5465/AMJ.2007.26279 183

Elgoibar, P., Munduate, L., \& Euwema, M. (2016). Building Trust and Constructive Conflict Management in Organizations (P. Elgoibar, L. Munduate, \& M. Euwema (eds.)). Springer Netherlands. https://doi.org/10.1007/9783-319-31475-4_1

Enwereuzor, I. K., Adeyemi, B. A., \& Onyishi, I. E. (2020). Trust in leader as a pathway between ethical leadership and safety compliance. Leadership in Health Services, 33(2), 201-219. https://doi.org/10.1108/LHS-09-20190063

Erdem, F., \& Ozen, J. (2003). Cognitive and affective dimensions of trust in developing team performance. Team Performance Management: An International Journal, 9, 131-135.

https://doi.org/10.1108/1352759031049 3846

Fam, I. M., Nikoomaram, H., \& Soltanian, A. (2012). Comparative analysis of creative and classic training methods in health, 
safety and environment (HSE) participation improvement. Journal of Loss Prevention in the Process Industries, 25(2), 250-253. https://doi.org/10.1016/j.jlp.2011.11.003

Flin, R., \& Yule, S. (2004). Leadership for safety: Industrial experience. In Quality and Safety in Health Care (Vol. 13, Issue SUPPL. 2). https://doi.org/10.1136/qshc.2003.00955 5

Fruhen, L. S., Mearns, K. J., Flin, R., \& Kirwan, B. (2014). Skills, knowledge and senior managers' demonstrations of safety commitment. Safety Science, 69, 29-36. https://doi.org/10.1016/j.ssci.2013.08.024

Gonçalves, S. M. P., da Silva, S. A., Lima, M. L., \& Meliá, J. L. (2008). The impact of work accidents experience on causal attributions and worker behaviour. Safety Science, 46(6), 992-1001.

https://doi.org/10.1016/j.ssci.2007.11.002

Griffin, M. A., \& Neal, A. (2000). Perceptions of safety at work: a framework for linking safety climate to safety performance, knowledge, and motivation. Journal of Occupational Health Psychology, 5(3), 347358. https://doi.org/10.1037/10768998.5.3.347

Hardison, D., Behm, M., Hallowell, M. R., \& Fonooni, H. (2014). Identifying construction supervisor competencies for effective site safety. Safety Science, 65, 45-53. https://doi.org/10.1016/j.ssci.2013.12.013

Haslam, S. A., Adarves-Yorno, I., Postmes, T., \& Jans, L. (2013). The Collective Origins of Valued Originality: A Social Identity Approach to Creativity. Personality and Social Psychology Review, 17(4), 384-401. https://doi.org/10.1177/1088868313498 001

Hayes, A. (2013). Integrating Mediation and Moderation Analysis: fundamentals using PROCESS. In Introduction to Mediation, Moderation and Conditional Process Analysis.

Hofmann, D. A., Morgeson, F. P., \& Gerras, S. J. (2003). Climate as a moderator of the relationship between leader-member exchange and content specific citizenship: Safety climate as an exemplar. Journal of Applied Psychology, 88(1), 170-178. https://doi.org/10.1037/00219010.88.1.170

Hofstede, G., Hofstede, G. J., \& Minkov, M. (2010). Cultures and Organizations: Sofware of the mind, 3rd ed. In Cultures and Organizations.

Irawanto, Dodi W., \& Ramsey, P. L. (2011). Paternalistic leadership and employee responses in Javanese culture. Gadjah Mada International Journal of Business, 13(2),
185-203.

https://doi.org/10.22146/gamaijb.5490

Irawanto, Dodi W., Ramsey, P. L., \& Tweed, D. C. (2012). Exploring paternalistic leadership and its application to the Indonesian public sector. International Journal of Leadership in Public Services, 8(1), 4-20. https://doi.org/10.1108/1747988121123 0637

Irawanto, Dodi Wirawan. (2009). An Analysis Of National Culture And Leadership Practices In Indonesia. Journal of Diversity Management (JDM), 4(2), 41-48. https://doi.org/10.19030/jdm.v4i2.4957

Jia, J., Zhou, S., Zhang, L., \& Jiang, X. (2020). Exploring the influence of paternalistic leadership on voice behavior: A moderated mediation model. Employee Relations, 42(2), 542-560. https://doi.org/10.1108/ER-062019-0263

Jiang, L., Li, F., Li, Y. J., \& Li, R. (2017). Leadermember exchange and safety citizenship behavior: The mediating role of coworker trust. Work, 56(3), 387-395. https://doi.org/10.3233/WOR-172504

Lee, D., Coustasse, A., \& Sikula, A. (2011). Transformational leadership and workplace injury and absenteeism: Analysis of a National Nursing Assistant Survey. In Health Care Management Review (Vol. 36, Issue 4, pp.

380-387). https://doi.org/10.1097/HMR.0b013e318 2100bf7

Lingard, H., Zhang, R. P., \& Oswald, D. (2019). Effect of leadership and communication practices on the safety climate and behaviour of construction workgroups. https://doi.org/10.1108/ECAM-01-20180015

Mohammadfam, I., Ghasemi, F., Kalatpour, O., \& Moghimbeigi, A. (2017). Constructing a Bayesian network model for improving safety behavior of employees at workplaces. Applied Ergonomics, 58, 35-47. https://doi.org/10.1016/j.apergo.2016.05. 006

Mullen, J. E., \& Kevin Kelloway, E. (2009). Safety leadership: A longitudinal study of the effects of transformational leadership on safety outcomes. Journal of Occupational and Organizational Psychology, 82(2), 253272.

https://doi.org/10.1348/096317908X325 313

Neal, A. (2002). Safety Climate and Safety Behaviour. September. https://doi.org/10.1177/0312896202027 $01 \mathrm{~S} 08$

Neal, A., \& Griffin, M. A. (2006). A Study of the 
Lagged Relationships among Safety Climate, Safety Motivation, Safety Behavior, and Accidents at the Individual and Group Levels A Study of the Lagged Relationships Among Safety Climate, Safety Motivation, Safety Behavior , and Accident. June 2014. https://doi.org/10.1037/00219010.91.4.946

Podsakoff, P. M., MacKenzie, S. B., Lee, J. Y., \& Podsakoff, N. P. (2003). Common Method Biases in Behavioral Research: A Critical Review of the Literature and Recommended Remedies. In Journal of Applied Psychology (Vol. 88, Issue 5, pp. 879-903). https://doi.org/10.1037/00219010.88.5.879

Purba, D. E., Oostrom, J. K., Born, M. P., \& Van Der Molen, H. T. (2016). The relationships between trust in supervisor, turnover intentions, and voluntary turnover: Testing the mediating effect of on-the-job embeddedness. Journal of Personnel Psychology, 15(4), 174-183. https://doi.org/10.1027/18665888/a000165

Rawat, P. S., \& Lyndon, S. (2016). Effect of paternalistic leadership style on subordinate's trust: an Indian study. Journal of Indian Business Research, 8(4), 264-277. https://doi.org/10.1108/JIBR-05-2016-
0045

Reason, J., Manstead, A., Stephen, S., Baxter, J., \& Campbell, K. (1990). Errors and violations on the roads: A real distinction? Ergonomics, 33(10-11), 1315-1332. https://doi.org/10.1080/0014013900892 5335

Tian, Q., \& Sanchez, J. I. (2017). Does paternalistic leadership promote innovative behavior? The interaction between authoritarianism and benevolence. Journal of Applied Social Psychology, 47(5), 235-246. https://doi.org/10.1111/jasp.12431

Yang, J., Mossholder, K. W., \& Peng, T. K. (2009). Supervisory procedural justice effects: The mediating roles of cognitive and affective trust. Leadership Quarterly, 20(2), 143-154. https://doi.org/10.1016/j.leaqua.2009.01. 009

Zhao, H. (2014). Relative leader-member exchange and employee voice. Chinese Management Studies. https://doi.org/10.1108/cms-01-20130016

Zohar, D. (2010). Thirty years of safety climate research: Reflections and future directions. Accident Analysis and Prevention, 42(5), 1517-1522.

https://doi.org/10.1016/j.aap.2009.12.019 